\title{
EFFECT OF FACE LAYER MANIPULATION ON THE DENSITY PROFILE AND PROPERTIES OF LOW DENSITY PARTICLEBOARD
}

\author{
Shupin Luo, Li Gao, Wenjing Guo \\ Chinese Academy of Forestry \\ Beijing, China \\ (Received March 20I9)
}

\begin{abstract}
Density reduction has gradually become a trend for the particleboard and furniture industries due to increased price and insufficient supply of wood. However, reduced density of the panels by the simple reduction of the wood material comes along with deterioration of the properties. In this study, to achieve sufficient properties (bending properties in particular), the particle moisture content (MC) and geometry in face layers were manipulated to manufacture low density particleboards $\left(500 \mathrm{~kg} \cdot \mathrm{m}^{-3}\right)$, with the core layer composed of a mixture of wood particles $(92.5 \mathrm{wt} \%)$ and expanded polystyrene $(7.5 \mathrm{wt} \%)$. This strategy was assumed to increase face layer density and generate a more pronounced vertical density profile, which is expected to improve panel properties. The density profile, mechanical properties and dimensional stability of the particleboards were investigated. Results showed that increasing the moisture content of face layer particles from $8 \%$ to $16 \%$ or using small-sized particle in face layer resulted in a more pronounced density profile, as well as using fiber in face layer. However, the higher density in the face layer was not necessarily related with better mechanical performance. The optimum physic-mechanical properties were obtained with the board of face layer made of $16 \% \mathrm{MC}$ fiber, which met the requirements for P2 boards used in dry conditions (EN 312).
\end{abstract}

KEYWORDS: Low density particleboard, face layer, moisture content, particle geometry, density profile, panel properties.

\section{INTRODUCTION}

Nowadays, density reduction of wood-based panels has attracted interest at both academic and industrial levels, because of shortage and increasing price for wood resources (Gao et al. 2018, Parlin et al. 2014, Shalbafan et al. 2015). Prevalence of ready-to-assemble and flat pack furniture is driving the development of low density panels as well. Lightweight wood-based panels bring 
many advantages such as more rational utilization of wood, easier transportation and handling, lower transportation cost due to mass reduction (Barbu 2016, Monteiro et al. 2018).

With an estimated production capacity of about 110.2 million $\mathrm{m}^{3}$ worldwide in 2016, particleboard is one important type of wood-based panels, commonly used in the furniture. Currently, the average density of particleboard in the market is about $620 \sim 720 \mathrm{~kg} \cdot \mathrm{m}^{-3}$ (Report of Chinese Particleboard Industry 2016). According to ASTM D1554-10, particleboard with a density of less than $640 \mathrm{~kg} \cdot \mathrm{m}^{-3}$ is classified as low density particleboard (Monteiro et al. 2019). One interesting approach to achieve the density reduction of particleboards is partly substituting wood particles with non-wood light fillers. Materials like foamed starch (Monteiro et al. 2016), dried distillers grains with solubles (Sundquist and Bajwa 2016), expanded polystyrene (PS) (Bajzová et al. 2018) and expandable microspheres (Shalbafan et al. 2012b) have been reported to be applied in the core layer of particleboard. BASF company developed a technology for producing lightweight particleboards called Kaurit ${ }^{\circledR}$ Light, with the core layer comprised of the mixture of wood particles and foamed PS beads, achieving 20 30\% lower density than the conventional particleboard (Monteiro et al. 2018). Shalbafan et al. (2012a; 2013) produced ultra-lightweight sandwich particleboards with a density around $300 \mathrm{~kg} \cdot \mathrm{m}^{-3} \mathrm{using}$ only thermo-sensitive expandable PS as core layer material, but the bending strength did not meet the requirement of P2 boards according to EN 312. Dziurka et al. (2015) manufactured particleboards (density reduced to $500 \mathrm{~kg} \cdot \mathrm{m}^{-3}$ ) using rape straw (or wood chips) and expanded polystyrene (7 wt \%) in the core layer. It was found that the requirement of mechanical strength for particleboards intended for interior application (EN 312/ P2 boards) was not fulfilled. One of the reasons for the reduced properties of density-decreased particleboards is considered as the increased proportion of cavities and fewer adhesive bonding between particles (Bajzová et al. 2018, Benthien and Ohlmeyer 2017). Introduction of PS beads or other light fillers can fill up the cavities between wood particles, making the internal structure more uniform (Dziurka et al. 2015). However, the positive effect of light fillers cannot completely compensate for the decreased board properties.

One strategy to solve this problem is optimizing the panel's density profile via re-engineering the mat structure (Benthien et al. 2017). Vertical density profile in the thickness direction is considered as a crucial characteristic that correlates with performance of wood-based panels (Schulte and Frühwald 1996, Wang and Winistorfer 2000, Lee et al. 2017). The formation of density profile is influenced mainly by furnish moisture condition, mat structure, and pressing environment (Wong et al. 1999, Hunt et al. 2017). Literature reported that the difference between face layer and core layer density in the three-layer particleboard became smaller with reducing density (Benthien and Ohlmeyer 2016, Wong et al. 1999). To achieve a distinct density profile in low density particleboards, the wood particles in the core layer need to have a high compression resistance (Schneider et al. 2018). Benthien and Ohlmeyer investigated the effect of mat structure on the properties of lightweight particleboards (Benthien and Ohlmeyer 2016, 2017). Results revealed that the internal bond strength and dimensional stability were improved by changing face-to-core layer ratio, core layer resin content and core layer particle orientation, but the bending properties was not affected. To achieve sufficient mechanical properties, bending in particular, a pronounced density profile with higher density face layer is supposed to be an important factor, since the face layers of the panel bear most of the load during bending (Wong et al. 1998). Further research on face layer optimization is required to achieve higher density face layer in lightweight particleboards.

This study aims to produce low density particleboards $\left(500 \mathrm{~kg} \cdot \mathrm{m}^{-3}\right)$ using wood particles and expanded PS foam as raw materials, which meet the required property requirements of EN 312/ P2 boards. Towards this goal, the particle size and MC in face layers was manipulated 
to achieve a pronounced vertical density profile. The change in the density profile and its influence on the mechanical and physical properties of particleboards were investigated.

\section{MATERIALS AND METHODS}

\section{Raw materials}

Poplar (Populus spp.) particles (air-dried moisture content of about 8\%) were provided by Ningfeng Wood-based Panels Corporation, China. The particles were sieved and divided into three fractions: fine (less than $0.5 \mathrm{~mm})$, medium $(0.5-1 \mathrm{~mm})$ and coarse $(1-4 \mathrm{~mm})$ for use (Fig. 1).

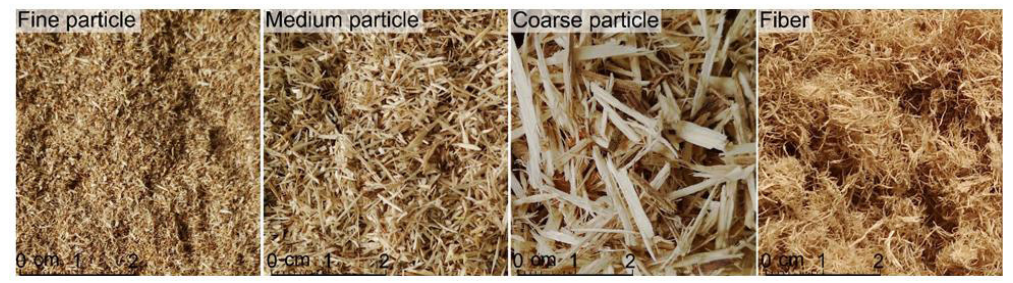

Fig. 1: Wood particle and fiber used for manufacturing of low density particleboard.

Poplar wood fibers were bought from the Chinese Academy of Forestry (Beijing, China). An optical impression of the four types of wood raw material can be obtained in Fig. 1. Expanded polystyrene foams ( $4-6 \mathrm{~mm}$ in diameter) with a density of $50-60 \mathrm{~kg} \cdot \mathrm{m}^{-3}$ was used as non-wood light fillers. A polymeric diphenylmethane di-isocyanate (PMDI) resin, WANNATE ${ }^{\circledR}$ PM-200 (viscosity: 150-200 $\mathrm{mPa} \cdot \mathrm{s}$ at $25^{\circ} \mathrm{C}, \mathrm{NCO}$ content: $30.5-32.0 \mathrm{wt} \%$, density: $1.22-1.25 \mathrm{~g} \cdot \mathrm{cm}^{-3}$ at $25^{\circ} \mathrm{C}$ ), was obtained from the Wanhua Corporation, Beijing, China. Acetone was used as a resin diluent for better adhesive distribution.

\section{Particle size distribution analysis}

Particle size distribution of the fine, medium and coarse particle sample was measured using the image analysis-based particle size measurement equipment (SCREENCAM 100 Optical Lab Screen for Wood Chips, IMAL-PAL GROUP, Italy). The wood particles were separated by the system without altering their dimensional characteristics, imaged by a digital camera, and analyzed by the software. The distribution of wood particles was given as a percentage over the total volume based on their dimensions. Approximately 100,000 particles were evaluated for each sample.

\section{Particleboards manufacturing}

Three layered particleboards with a target density of $500 \mathrm{~kg} \cdot \mathrm{m}^{-3}$ were manufactured. The thickness was set for $15 \mathrm{~mm}$ in all panel variations. The core layer was composed of expanded PS foams and air-dried coarse wood particles at the weight ratio of 3:37. In the case of face layer, a type of material, MC and layer thickness were manipulated, as summarized in Tab. 1. 
Tab. 1: Formulation of the face layer for the $15 \mathrm{~mm}$ low density particleboards and their actual mean densities.

\begin{tabular}{|c|c|c|c|c|}
\hline \multirow[b]{2}{*}{ Code } & \multicolumn{3}{|c|}{ Face layer } & \multirow{2}{*}{$\begin{array}{c}\text { Mean density } \\
\left(\mathrm{kg} \cdot \mathrm{m}^{-3}\right)\end{array}$} \\
\hline & Material type & $\begin{array}{c}\text { Moisture content } \\
(\%)\end{array}$ & $\begin{array}{c}\text { Thickness } \\
\text { (mm) }\end{array}$ & \\
\hline Fine particle-8MC-1.5 & fine particle & 8 & 1.5 & 489 \\
\hline Fine particle-16MC-1.5 & fine particle & 16 & 1.5 & 499 \\
\hline Med particle-8MC-1.5 & medium particle & 8 & 1.5 & 488 \\
\hline Med particle-16MC-1.5 & medium particle & 16 & 1.5 & 504 \\
\hline Med particle-16MC-2.5 & medium particle & 16 & 2.5 & 507 \\
\hline Fiber-8MC-1.5 & fiber & 8 & 1.5 & 463 \\
\hline Fiber-16MC-1.5 & fiber & 16 & 1.5 & 482 \\
\hline
\end{tabular}

To obtain 16\% MC, the wood particles were sprayed with required amount of deionized water and stored in zip lock bags. Resin content was $7 \%$ for core layer and $10 \%$ for face layer (based on the dry mass). The three-layered mat $(340 \times 360 \mathrm{~mm})$ was made manually, and pressed at $120^{\circ} \mathrm{C}$ for 20 min using thickness gauges. Then the boards were cooled down at ambient conditions and conditioned prior to sample cutting. The boards were produced in two replications.

\section{Evaluation of particleboards}

Cross-sectional density profile was measured on a DENSE-LAB X densitometry (EWS, Germany), using $X$ ray transmitted across the thickness of sample at a scanning speed of $0.5 \mathrm{~mm} \cdot \mathrm{s}^{-1}$. Mechanical properties were analysed by determining internal bond strength (IB) according to EN 319, modulus of rupture (MOR) and modulus of elasticity (MOE) according to EN 310, using an Instron 5582 universal testing machine. Physical properties were characterized by measuring thickness swelling (TS) (EN 317) after $2 \mathrm{~h}$ of water immersion at $20^{\circ} \mathrm{C}$. Eight replicates were tested for MOR and MOE, and twelve replicates were tested for IB and TS, respectively.

\section{Statistical analysis}

Data analysis was performed using the Statistical Package for the Social Science (SPSS software, IBM). Comparison of mean values was conducted to evaluate whether the differences between the properties of the particleboards manufactured at different conditions are significant or not. ANOVA test was performed by using Tukey-test method, at a significance level of $\alpha=0.05$.

\section{RESULTS AND DISCUSSION}

\section{Particle size characterization}

The particle size distributions (length, width and slenderness) are shown in Fig. 2. It can be seen that the coarse particle sample has the largest dimensions with peaks in the distribution at longer lengths and widths than medium and fine particle. The fine particle sample has the smallest average length and width. The slenderness is the ratio between the length and width, displayed as a box plot graph that has three marks $\left(25^{\text {th }}, 50^{\text {th }}\right.$ and $75^{\text {th }}$ percentile). This is useful for seeing how a sample which has passed through the same shifter is formed. The slenderness of coarse particle sample and medium particle sample exhibited a quite similar trend. 

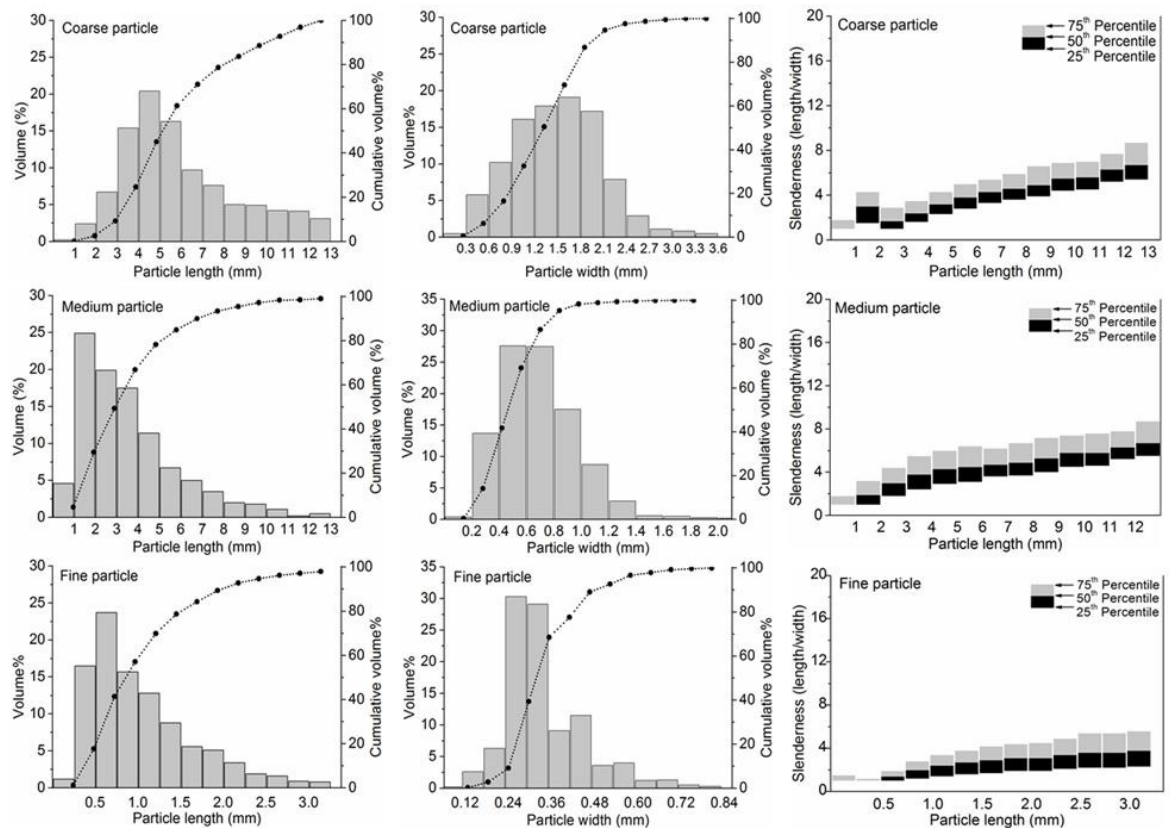

Fig. 2: Histogram of the distribution and cumulative distribution of the particle length and width, and Box plot of particle slenderness.

\section{Density profile}

In the current study, the coarse particle was applied in the core layer, due to the large particles are expected to give better mechanical strength, while the small ones was good for surface quality (Monteiro et al. 2018). The internal structure of the particleboards is shown in Fig. 3. The density profile of the particleboards generally resembles a U-shape, as shown in Fig. 4. The mean density of all these particleboards is similar (Tab. 1). For panels with different material type and $\mathrm{MC}$ in face layers, the density profiles varied. The increase in the face MC led to slimmer and higher peaks near to the surface (dotted lines). This is probably because the face layers were more compacted due to the increased plasticity of the moist particles, resulting in a larger difference between face and core densities (Wong et al. 1998).

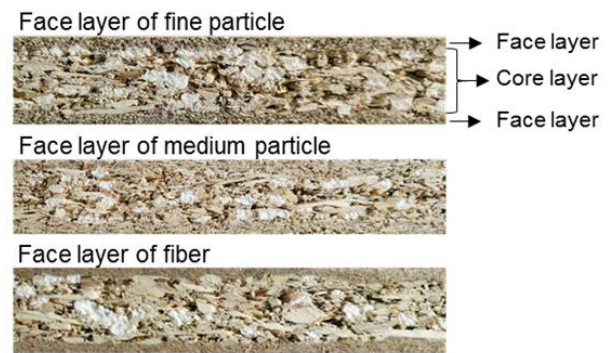

Fig. 3: Internal structure of $15 \mathrm{~mm}$ three-layer particleboards with $1.5 \mathrm{~mm}$ face layer made from fine particle, medium particle and fiber, respectively. 
In order to clarify the effect of face layer thickness, the particleboards with $2 \mathrm{~mm}$ face layer made of medium particle was investigated as well. When the thickness of face layers was increased from $1.5 \mathrm{~mm}$ to $2 \mathrm{~mm}$, the core layer particles were less compacted. In the density profile, this is expressed by a lower core region and less steep decrease of density from surface to core layer.
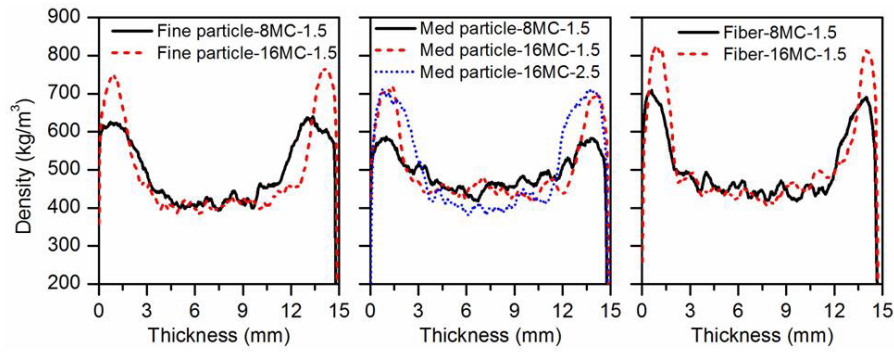

Fig. 4: Vertical density profiles of particleboards with different formulations. The sample code refers to Tab. 1.

When the face layer was altered from medium particle to fine particle, the contrast between face and core layer density became higher. This is probably due to that the compression resistance of small particles is lower than that of large particles (Benthien et al. 2017). To achieve highly compressed face layers, wood fiber was chosen as another face material. When the wood particle was replaced with fibre, a significantly more slender peak in the surface density was observed. Results indicated that at a similar mean density level, increasing the $\mathrm{MC}$ of face layer particles or using small-sized particle in face layer resulted in a more pronounced density profile, as well as using fiber in face layer.

\section{Bending properties}

As expected, the increase of face MC has a positive effect on the bending properties (Fig. 5). By increasing the face $\mathrm{MC}$ from $8 \%$ to $16 \%$, the MOR raised by $5 \%, 22 \%$ and $11 \%$ for the panels with face of fine particle, medium particle and fibre, respectively, but the increased could not be detected as significant. The general effect of MC on MOE was similar with that on MOR.
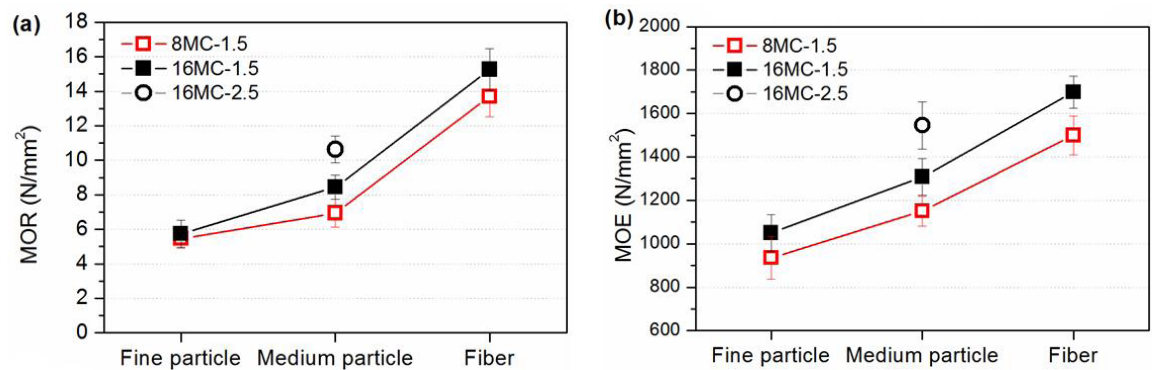

Fig. 5: MOR (a) and MOE (b) values of $15 \mathrm{~mm}$ particleboard. Note: the sample code refers to Tab. 1.

Comparing bending properties of particleboards with three types of face layer revealed the following trend: fine particle < medium particle < fibre. Despite the higher peak density of fine particle than medium particle, the sample with medium particle face layer showed higher MOR and MOE. Therefore, the presence of higher density in the face layer does not 
necessarily result in better bending performance. The panel with face layers of $16 \% \mathrm{MC}$ fiber met the minimum requirements of MOR and MOE for a conventional particleboard (EN312/P2: $13 \mathrm{~N} \cdot \mathrm{mm}^{-2}$ for MOR and $1600 \mathrm{~N} \cdot \mathrm{mm}^{-2}$ for MOE). Whereas, Dziurka et al. (2015) produced low density particleboards using mixture of wood chips and expanded PS beads ( $7 \mathrm{wt} \%$ ) as core layer material, but the boards with density of $500 \mathrm{~kg} \cdot \mathrm{m}^{-3}$ cannot meet the requirement of MOR according to EN312/ P2. This is probably due to that the larger aspect ratio of fiber promoted their entanglement, which could strengthen the face layer.

In the case of $16 \% \mathrm{MC}$ medium particle, by raising the face thickness from $1.5 \mathrm{~mm}$ to $2 \mathrm{~mm}$, the MOR significantly increased from $8.4 \mathrm{~N} \cdot \mathrm{mm}^{-2}$ to $10.6 \mathrm{~N} \cdot \mathrm{mm}^{-2}$ and MOE from $1312 \mathrm{~N} \cdot \mathrm{mm}^{-2}$ to $1546 \mathrm{~N} \cdot \mathrm{mm}^{-2}$, which was very close to the requirements of EN312. Boards with thicker face layers will be further investigated in our next study.

\section{Internal bond (IB) strength}

The IB values of the particleboards are shown in Fig. 6. Increasing face layer MC to $16 \%$ resulted in a slight higher $\mathrm{IB}$, which was consistent with increased face density. This was probably because higher MC caused more effective internal cohesion. It is noted that in the case of fine particle, the destruction of the samples during IB test occurred within the face layer occasionally. This might be attributed to the weak adhesion between powder-like fine particles despite higher glue content of the face layer.

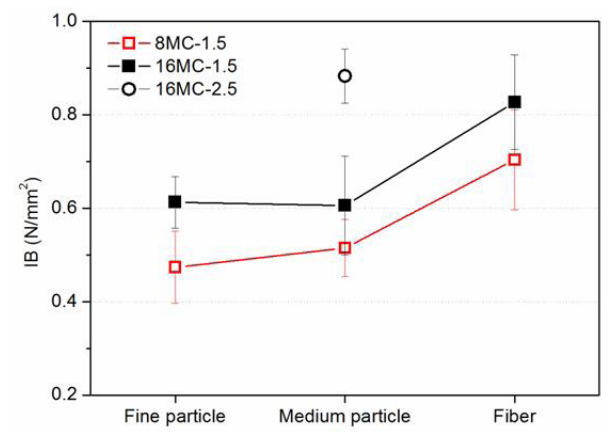

Fig. 6: Internal bond strength of $15 \mathrm{~mm}$ low density particleboard with different face layer material and MC. Note: the sample code refers to Tab. 1.

The difference between the IB values of particleboards with fine particle and medium particle in face layers was statistically insignificant, whereas using fiber in face layer significantly raised the IB. According to EN 312, IB values of all the boards outperformed the minimum requirements for $\mathrm{P} 2$ boards $\left(0.35 \mathrm{~N} \cdot \mathrm{mm}^{-2}\right)$. Compared with the conventional particleboard of similar mean density, the IB values in this study were higher than that in previous study by Boruszewski et al. (2016) (less than $0.25 \mathrm{~N} \cdot \mathrm{mm}^{-2}$ ).

The maximum value of IB $\left(0.88 \mathrm{~N} \cdot \mathrm{mm}^{-2}\right)$ was obtained in the panel with $2.5 \mathrm{~mm}$ face layer (medium particle with 16\% MC). The significantly raised IB value in the Med particle$16 \mathrm{MC}-2.5$ sample is probably due to that its density profile presented a narrower zone of low density region in core layer (Fig. 4), therefore a lower possibility for failure occurred in the weak point within the core layer (Wong et al. 1999). 


\section{Thickness swelling (TS)}

TS were determined after immersion in water for $2 \mathrm{~h}$ (Fig. 7). The $2 \mathrm{~h}$ TS of panels in the present study was lower than that of particleboards made of wooden particles with similar density, because PS is an inherent hydrophobic polymer (Shalbafan et al. 2015). Since the formulation of core layer kept unchanged, the TS of these samples was depended largely on the surface layer. The 16\% MC face layer boards had lower TS than that of $8 \%$ MC boards manufactured under same processing conditions. The difference is probably due to that higher $\mathrm{MC}$ in face layer caused higher compressibility of the particles (or fiber) and hence less cavities for water absorption (Maraghi et al. 2018). In general, the TS showed negative correlations with the face layer density.

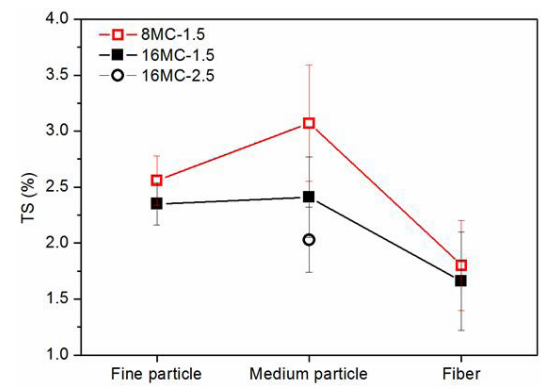

Fig. 7: Thickness swelling (TS) of particleboards after $2 \mathrm{~b}$ water soaking.

At the same MC level, TS did not change significantly as face layer changed from fine particle to medium particle, which is consistent with their similar density profile. But the TS of board with fiber as face layer material shows a significant lower TS than that of the other two materials. This is the consequence of a more compacted surface layer that caused less accessibility to the hydroxyl groups. The TS decreased with the increase of face layer thickness from $1.5 \mathrm{~mm}$ to $2.5 \mathrm{~mm}$ in $16 \mathrm{MC}$ boards, partially due to a higher proportion of more compressed face layer that is tight and hard.

\section{CONCLUSIONS}

This study showed that increasing the MC from $8 \%$ to $16 \%$ or substituting particle with fibre in face layer resulted in a more pronounced density profile, which had a positive influence on the MOR, MOE, IB and dimensional stability of the resulting particleboards. But the improvement of properties caused by increased MC cannot be detected as significant. The bending properties of panels were significantly enhanced when the face layer changed from fine particle to medium particle; whereas the internal bond strength and thickness swelling was not found to be affected. Compared to wood particle, using fibers as face layer material led to remarkable panel property improvements, probably due to its low compression resistance that resulted in the highly compacted face. Additionally, the entanglement between fibers could strengthen the face layer. The requirement of physic-mechanical properties for boards intended for interior design used in dry conditions (EN 312/ P2) was fulfilled by panels with 16\% MC fiber as face layer. Further research is needed to produce low density particleboards using particle as face layer that meet required properties of a conventional particleboard. 


\section{ACKNOWLEDGEMENTS}

This study was financially supported by the Special Fund of Chinese Academy of Forestry for Fundamental Scientific Research (No. CAFYBB2017ZX003-3) and the National Key Research and Development Program of China (No. 2018YFD0600301).

\section{REFERENCES}

1. Bajzová, L., Bekhta, P., Iždinský, J., Sedliačik, J., 2018: The effect of veneering on the properties of lightweight particleboard with expanded polystyrene. Acta Facultatis Xylologiae Zvolen 60 (1): 93-100.

2. Barbu, M.C., 2016: Evolution of lightweight wood composites. Pro Ligno 11: 21-26.

3. Benthien, J.T., Ohlmeyer, M., 2016: Influence of face-to-core layer ratio and core layer resin content on the properties of density-decreased particleboards. European Journal of Wood and Wood Products 75 (1): 55-62.

4. Benthien, J.T., Ohlmeyer, M., 2017: Enhancement of low-density particleboard properties by core layer particle orientation. European Journal of Wood and Wood Products 76(3): 1087-1091.

5. Benthien, J.T., Ohlmeyer, M., Schneider, M., Stehle, T., 2017: Experimental determination of the compression resistance of differently shaped wood particles as influencing parameter on wood-reduced particleboard manufacturing. European Journal of Wood and Wood Products 76 (3): 937-945.

6. Boruszewski, P., Borysiuk, P., Mamiński, M., Czechowska, J., 2016: Mat compression measurements during low-density particleboard manufacturing. BioResources 11(3): 6009-6919.

7. Dziurka, D., Mirski, R., Dukarska, D., Derkowski, A., 2015: Possibility of using the expanded polystyrene and rape straw to the manufacture of lightweight particleboards. Maderas. Ciencia y tecnología 17 (3): 647-656.

8. Gao, L., Tang, Q. Chen, Y., Wang, Z., Guo, W., 2018: Investigation of novel lightweight phenolic foam-based composites reinforced with flax fiber mats. Polymer Composites 39 (6): 1809-1817.

9. Hunt, J. F., Leng, W., Tajvidi, M., 2017: Vertical density profile and internal bond strength of wet-formed particleboard bonded with cellulose nanofibrils. Wood and Fiber Science 49 (4): 1-11.

10. Lee, S.H., Lum, W.C., Zaidon, A., Fatin-Ruzanna, J., Tan, L.P., Mariusz, M., Chin, K.L., 2017: Effect of post-thermal treatment on the density profile of rubberwood particleboard and its relation to mechanical properties. Journal of Tropical Forest Science 29 (1): 93-104.

11. Maraghi, M.M.R., Tabei, A., Madanipoor, M., 2018: Effect of board density, resin percentage and pressing temperature on particleboard properties made from mixing of poplar wood slab, citrus branches and twigs of beech. Wood Research 63 (4): 669-681.

12. Monteiro, S., Martins, J., Magalhães, F., Carvalho, L., 2016: Low density wood-based particleboards bonded with foamable sour cassava starch: Preliminary Studies. Polymers 8 (10): 354 .

13. Monteiro, S., Martins, J., Magalhães, F.D., Carvalho, L., 2018: Lightweight composites: Challenges, production and performance. In: Lignocellulosic Composite Materials (ed. Kalia, S.). Springer. Cham., Pp 293-322. 
14. Monteiro, S., Martins, J., Magalhães, F.D., Carvalho, L., 2019: Low density wood particleboards bonded with starch foam-study of production process conditions. Materials 12 (12): 1975.

15. Parlin, N.J., Davids, W.G., Nagy, E., Cummins, T., 2014: Dynamic response of lightweight wood-based flexible wall panels to blast and impulse loading. Construction and Building Materials 50: 237-245.

16. Schneider, M., Stehle, T., Benthien, J.T., Ohlmeyer, M., 2018: Stiffness modelling particles in the core layer for the manufacturing of wood-reduced particleboard. European Journal of Wood and Wood Products 76 (3): 947-952.

17. Schulte, M., Frühwald, A., 1996: Some investigations concerning density profile internal bond and relating failure position of particleboard. Holz als Roh- und Werkstoff 54 (5): 289-294.

18. Shalbafan, A., Dietenberger, M.A., Welling, J., 2012a: Fire performances of particleboards continuously produced in a one-step process. European Journal of Wood and Wood Products 71 (1): 49-59.

19. Shalbafan, A., Luedtke, J., Welling, J., Fruehwald, A., 2013 properties of ultra-lightweight foam core particleboard: different core densities. Holzforschung 67 (2): 169-175.

20. Shalbafan, A., Luedtke, J., Welling, J., Thoemen, H., 2012 b: Comparison of core materials in innovative lightweight wood-based panels. European Journal of Wood and Wood Products 70 (1-3): 287-292.

21. Shalbafan, A., Tackmann, O., Welling, J., 2015: Using of expandable produce density particleboard. European Journal of Wood and Wood Products 74 (1): 15-22.

22. Sundquist, D.J., Bajwa, D.S., 2016: Dried distillers grains with solubles as multifunctional filler in low density wood particleboards. Industrial Crops and Products 89: 21-28.

23. Wang, S., Winistorfer, P.M., 2000: Fundamentals of vertical density profile in wood composites. Part II. Methodology of vertical density formation under dynamic conditions. Wood and Fiber Science 32 (2): 220-238.

24. Wong, E.D., Zhang, M., Wang, Q. Kawai, S., 1998: Effects of mat moisture and press closing speed on the formation of density profile and properties of particleboard. Journal of Wood Science 44 (4): 287-295.

25. Wong, E.D., Zhang, M., Wang, Q. Kawai, S., 1999: Formation of the density and its effects on the properties of particleboard. Wood Science and Technology 33 (4): 327-340.

\author{
Shupin Luo, Li Gao*, Wenjing Guo \\ Chinese Academy of Forestry \\ Research Institute of Wood Industry \\ No.i Dongxiaofu, Haidian District \\ BEIJING IOOOgI \\ China
}

*Corresponding author: wojiushig1@126.com. 